\title{
CONSTRUÇÃO DE LETREIRO EM CONCRETO ARMADO: UMA PROPOSTA DE METODOLOGIA ATIVA
}

CONSTRUCTION OF REINFORCED CONCRETE SIGN: AN ACTIVE METHODOLOGY PROPOSAL

Tatiane Isabel Hentges ${ }^{1}$, Tainá Seidel Durante ${ }^{2}$, Tania Valentin de Lima Fantin ${ }^{3}$

DOI: 10.37702/REE2236-0158.v40p353-364.2021

\begin{abstract}
RESUMO
A nova geração de discentes das engenharias vem mostrando que o atual modelo de ensino está cada vez mais defasado. Dessa forma, a adoção de atividades baseadas em metodologias ativas de ensino tem se destacado pela eficiência e otimização da aprendizagem. Com isso, este trabalho teve como objetivo descrever e avaliar os resultados da implantação de uma atividade prática realizada em uma disciplina final do curso de Engenharia Civil. A atividade foi caracterizada pela construção de letras de concreto armado para utilização como letreiro da instituição. Os alunos tiveram autonomia para determinar e planejar a forma de confecção das letras e, ao final, responderam a uma pesquisa de satisfação. Como resultados, verificou-se que cada grupo adotou materiais e métodos diferentes para executar sua letra. Além disso, percebeu-se a necessidade da adoção dos conhecimentos já obtidos ao longo do curso, bem como a aprendizagem e colaboração entre grupos. O questionário final evidenciou a satisfação dos alunos, a qual foi percebida no engajamento ao longo do semestre, refletindo o desejo da replicação da metodologia em outras disciplinas.
\end{abstract}

Palavras-chave: ensino; aula prática; metodologia ativa; letreiro de concreto; engenharia civil.

\begin{abstract}
The new generation of engineering students are showing that the current teaching model is increasingly out of date. Thus, adopting activities based on active teaching methodologies are standing out because of its efficiency and optimization of learning. In this way, this work aimed to describe and evaluate the results of the implementation of a practical activity carried out in a final discipline of the civil engineering course. The activity was characterized by the construction of reinforced concrete letters for use as an institution sign. The students had the autonomy to determine and plan the way of making the letters and, at the end, they answered a satisfaction survey. As a result, it was found that each group adopted different materials and methods to execute its letter. In addition, there was a need to use the knowledge already obtained during the course, as well as the learning and collaboration between groups. The final questionnaire showed students' satisfaction, which was perceived in their engagement throughout the semester, reflecting the desire to replicate the methodology in other disciplines.
\end{abstract}

Keywords: teaching; practical class; active methodology; concrete sign; civil engineering.

\footnotetext{
${ }^{1}$ Engenheira Civil. Professora no Mestrado em Engenharia Civil, Sanitária e Ambiental da UnC - Concórdia. tatiane.hentges@unc.br.

${ }^{2}$ Engenheira Civil. Mestranda em Engenharia Civil, Sanitária e Ambiental na UnC - Concórdia. tainadurante@gmail.com.

3 Engenheira Civil. Mestranda em Engenharia Civil, Sanitária e Ambiental na UnC - Concórdia. taniavlfantin@yahoo.com.br.
} 


\section{INTRODUÇÃO}

Metodologias ativas de ensino são, em síntese, ferramentas que buscam a motivação da autonomia do aluno (BARDINI; SPALDING, 2017) (MOTA; MARTINS, 2008). Tais ferramentas vêm sendo largamente pesquisadas e discutidas tendo em vista que o ensino superior ainda adota estratégias educacionais voltadas para um modelo de educação tradicional, principalmente os cursos de engenharias (SILVA et al., 2016). Nesse modelo, o aluno apenas recebe a teoria sem participar ativamente na obtenção dos conhecimentos, gerando uma limitação em sua formação. (SENADOR et al., 2016) (SILVA; CECÍLIO, 2007).

De acordo com Treicher (1967, apud BRESSANE et al., 2017), o envolvimento na realização de uma atividade leva à fixação de 90\% do aprendizado. Esse valor é reduzido para $10 \%$ quando há apenas leitura e $20 \%$ quando a matéria é recebida de forma verbal. A partir disso, a engenharia é uma das áreas que mais necessita de integração do conhecimento teórico e prático, levando em consideração tanto a complexidade lógica e matemática envolvida em seus conteúdos quanto o fato de ser uma ciência dedicada a transformar conhecimento em solução (BRESSANE et al., 2017).

As novas geração de discentes são capazes de realizar diversas atividades ao mesmo tempo e possuem acesso a várias fontes de informação de maneira muito mais simples e rápida quando comparada às demais gerações (BARDINI; SPALDING, 2017). Assim, metodologias ativas de ensino surgem como uma abordagem que otimiza o aprendizado, unindo o "saber" ao "fazer", à medida em que o professor deixa de ser a fonte de informações para atuar como facilitador, motivador e questionador. Enquanto isso, o aluno possui o papel ativo de busca e geração de conhecimento, desenvolvendo habilidades como foco, raciocínio, comunicação, trabalho em equipe, autonomia, iniciativa e pensamento crítico (ROCHA; LEMOS, 2014) (SANT'ANNA; FRANÇA, 2019) (BARDINI; SPALDING, 2017) (CORTEZ; PASSOLD, 2019).
O desafio para as instituições de ensino, entretanto, é a aplicação dessa abordagem, pois exige a criação de estratégias inovadoras que acompanhem as mudanças tecnológicas e sociais (NASCIMENTO, 2001). Além disso, entre as várias formas de aprender, é necessário que o conteúdo seja apresentado por completo, bem estruturado e de forma lógica, coerente com a realidade local e com as exigências do mercado de trabalho (BATTESINI; MATEUS, 2018) (CHINAGLIA; SANTOS, 2018) (CORRÊA, 2019).

Em razão disso, o objetivo deste estudo é descrever e avaliar os resultados de uma atividade prática, utilizada como metodologia ativa, proposta para uma turma de formandos em Engenharia Civil: a execução de um letreiro em concreto.

\section{METODOLOGIA}

Este trabalho foi desenvolvido ao longo da disciplina Tópicos Especiais II, que está inserida no $10^{\circ}$ semestre do curso de Engenharia Civil da Universidade do Contestado, junto ao campus Concórdia. Um dos objetivos da disciplina é desenvolver nos alunos a aplicação de conhecimentos obtidos ao longo de toda a graduação.

Dessa forma, uma das notas da disciplina foi a elaboração de concretos com diferentes relações água/cimento e contendo adição de fíler basáltico, que é resíduo de indústria de mineração da cidade. Foram testados o abatimento de tronco de cone, a resistência à compressão, a absorção de água e a resistividade elétrica das misturas executadas. A partir dos resultados obtidos, a turma optou por um dos traços para a aplicação nas letras de concreto.

\section{Desafio de construção das letras}

A segunda nota da turma consistiu no desafio de elaboração das letras da sigla da universidade (UnC) em concreto armado, sendo que estas deveriam ter a fonte e a proporção de dimensões iguais às da logomarca, conforme apresenta a Figura. Para isso, os quinze alunos foram divididos em três grupos e cada grupo deveria construir uma letra. 
Figura 1 - Logomarca (a) usada como base para dimensões das letras em concreto (b)

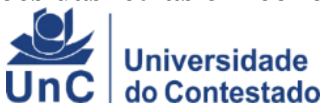

(a)

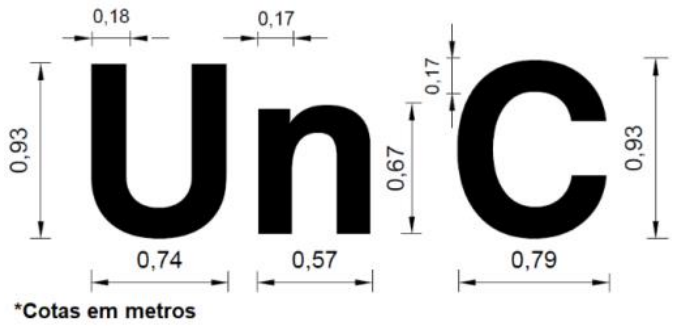

(b)

Fonte: elaborada pelas autoras.

A nota do desafio foi composta $50 \%$ pela execução da letra e $50 \%$ pela instalação desta em uma área de jardim do campus universitário. O letreiro deveria ficar em pé acima de uma base (sapata) também a ser executada em concreto armado. A participação na construção da base também compôs a nota dos últimos $50 \%$.

Para a execução do desafio foram fornecidas impressões das letras no tamanho real em que elas deveriam ser construídas e foi determinada uma espessura padrão de 15 centímetros. Os materiais e equipamentos necessários para a execução dos concretos (cimento, agregados graúdo e miúdo, aditivo, água, betoneira) bem como o aço empregado na construção foram fornecidos pela universidade. Em relação às fôrmas para as letras, foi dada total liberdade aos grupos para que definissem tanto como as executariam quanto quais materiais utilizariam. Assim, o material com o qual as fôrmas foram construídas foi obtido pelos próprios alunos, bem como a decisão de como desenvolver a montagem desta (escoramentos, gravatas, base) coube a eles.

O desafio deveria estar entregue até o último dia de aula e, com isso, o período total para conclusão do desafio foi de quatro meses.

\section{Questionário de satisfação}

Após a conclusão do desafio das letras foi desenvolvido um questionário para mensurar e melhor entender a satisfação dos alunos com a atividade prática desenvolvida. Esse questionário foi executado levando-se em conta que a atividade prática desenvolvida pelos alunos não é comum durante as etapas da graduação. Além disso, por meio das perguntas foi analisada a dificuldade percebida pelos alunos em integrar e aplicar os conhecimentos obtidos ao longo do curso de graduação.

As perguntas aplicadas são apresentadas na Tabela , tendo sido montadas de forma que as respostas fossem objetivas. As respostas, por sua vez, foram desenvolvidas em cinco níveis de satisfação e foram enviadas por meio da plataforma Google Formulários. O retorno do questionário não era obrigatório e não contava pontos na média final da disciplina. $O$ questionário também não coletou dados pessoais dos alunos, porém permitiu um feedback por e-mail.

Tabela 1 - Questionário sobre satisfação da atividade

\begin{tabular}{cc}
\hline Pergunta & Resposta \\
\hline Você considerou esta & Nada \\
atividade difícil? & Pouco \\
& Indiferente \\
& Sim \\
Muito
\end{tabular}

Fonte: elaborada pelas autoras. 


\section{RESULTADOS}

\section{Execução das letras}

O primeiro grupo a montar sua fôrma para o desafio foi o responsável pela letra " $n$ ". Esta foi executada com laterais em placas de MDF com diferentes espessuras (Figura ). Nas laterais retas foram empregadas placas com espessura de 10 milímetros (mm), já nas áreas com arqueamento foi empregado MDF com $3 \mathrm{~mm}$. Essa solução foi adotada para que as primeiras atuassem como elementos rígidos que fixassem a letra, já que as demais necessitavam de maior flexibilidade para não haver ruptura nas curvas, mantendo o acabamento liso. Ainda, foram inseridas gravatas junto às "pernas" da letra para evitar possível abaulamento. $\mathrm{Na}$ região superior da letra, garantiu-se a fixação do arco maior com a placa de maior espessura (formando ângulo agudo) de forma que não houvesse risco de deformidades. O mesmo ocorreu com o arco interno, onde as gravatas foram fixadas a uma altura em que este não sofresse alterações. A armadura e os estribos executados para a letra foram feitos em aço CA50 de com 6,3 mm de diâmetro, conforme verifica-se na Figura, e nesta foram colocados espaçadores para assegurar uma espessura de cobrimento mínima de $25 \mathrm{~mm}$.

Figura 2 - Fôrma e armadura da letra "n"

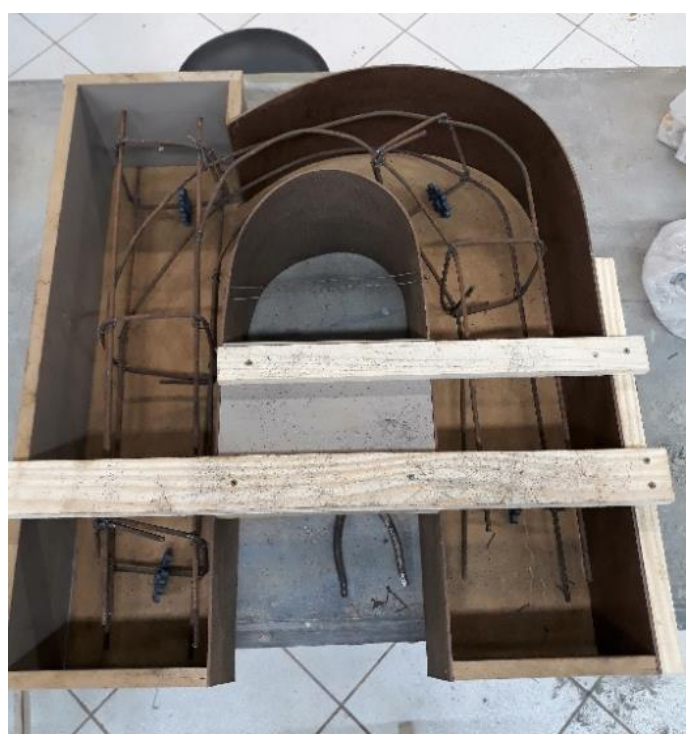

Fonte: acervo das autoras.

O concreto executado para enchimento da fôrma foi escolhido pelos alunos, tendo relação água/cimento de 0,55 , consumo de cimento de $375 \mathrm{~kg} / \mathrm{m}^{3}$ e adição de $10 \%$ de fíler basáltico. Para garantir a qualidade da textura superficial e evitar possíveis bolhas ou falhas de concretagem, foi adicionado aditivo superplastificante até que a mistura atingisse a fluidez de um concreto autoadensável. Assim, foi necessário apenas a aplicação de alguns golpes na parte externa da fôrma. Ainda, foi passado desmoldante em toda a área interna da fôrma. Percebe-se, pela Figura, que não houve fugas com vazamento de pasta de cimento.

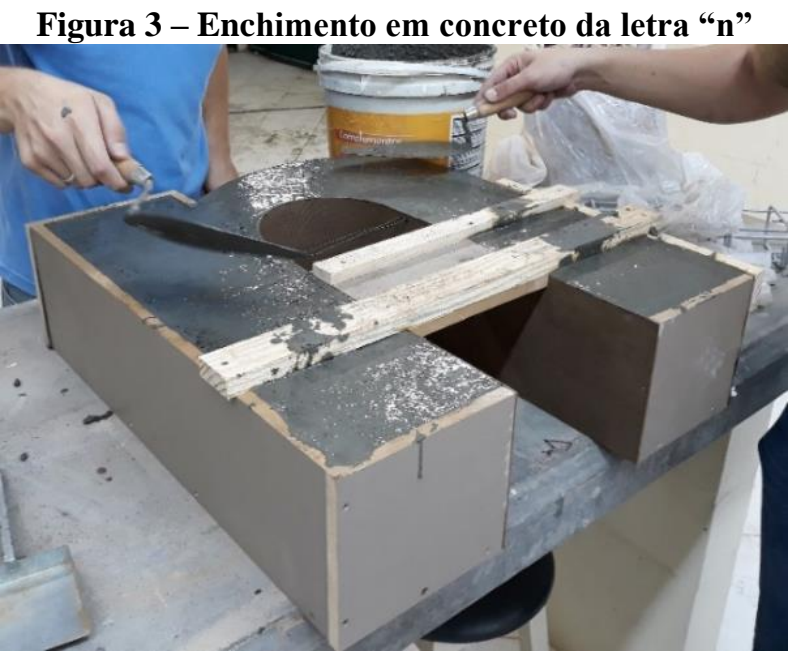

Fonte: acervo das autoras.

O segundo grupo a concluir sua letra foi o que executou a letra "C". Esses alunos optaram por realizar a fôrma em madeira. Assim, para o contorno em curva da letra foram utilizadas duas placas com 2,5 $\mathrm{mm}$ de espessura, sendo que estas foram coladas uma na outra. A opção pelo emprego duplo das placas foi para se obter maior robustez, conforme pode ser visto na Figura . Para a base da letra foi executada uma placa de madeira com dimensões de 0,85 x 1,00 $\mathrm{m}$.

Ao longo de todo o perímetro da fôrma foram inseridas ripas de madeiras utilizadas como calços curvos que guiaram o ângulo de curvatura padrão determinado. Ainda, foram fixadas escoras externas para apoiar as placas e garantir que o esforço aplicado pelo concreto não gerasse abaulamento. Por fim, nas extremidades de início e fim da letra foi feito fechamento com placas de madeira de $25 \mathrm{~mm}$ de espessura, as quais tiveram suas laterais no mesmo formato das demais escoras, inserindo mais um ponto de rigidez no sistema. Para fixar 
o espaço entre essas extremidades, foi colocada outra placa perpendicular a estas.

Figura 4 - Fôrma construída para execução da letra

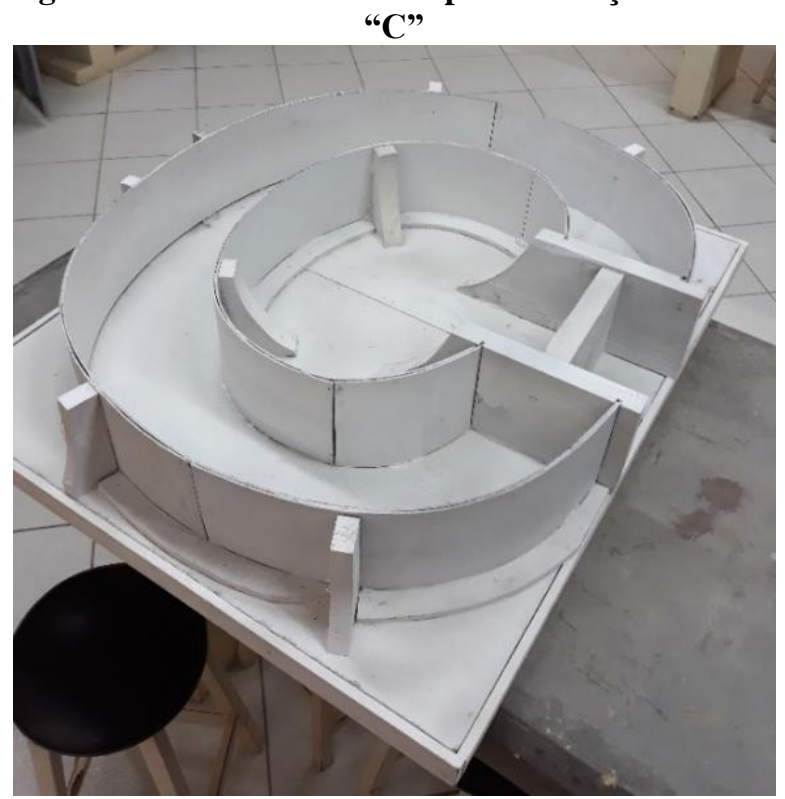

Fonte: acervo das autoras.

Conforme pode ser visto na Figura, a armadura dessa letra foi executada de forma similar à da letra "n", tendo sido montada junto dos estribos em aço CA-50. Assim como na letra "n", esta também recebeu espaçadores para garantia da espessura de cobrimento e foi aplicado desmoldante em toda a área interna. $\mathrm{O}$ concreto empregado na moldagem teve $o$ mesmo traço da letra "n", porém foi aplicado com menos fluidez (menor teor de aditivo superplastificante) e, dessa forma, foi necessário realizar o adensamento deste com barra metálica, além dos golpes junto às laterais. Conforme visto na Figura, nesta fôrma também não houve vazamento de pasta de cimento, ocorrendo apenas fuga do excesso de desmoldante (líquido menos viscoso) na parte inferior, na ligação entre base e contorno.

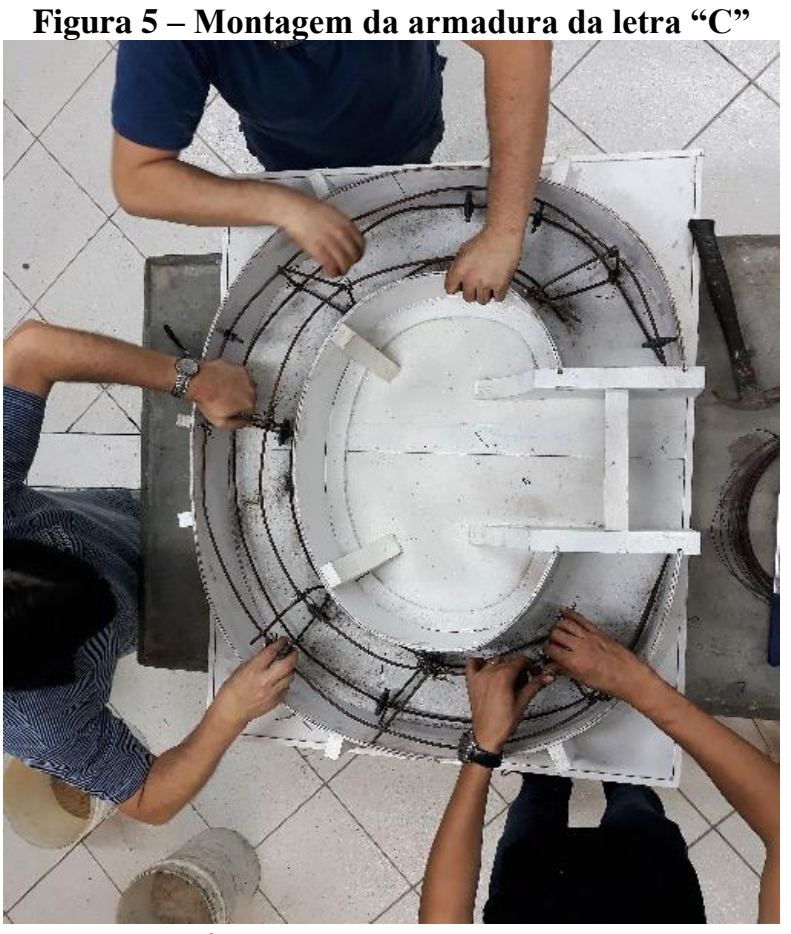

Fonte: acervo das autoras.

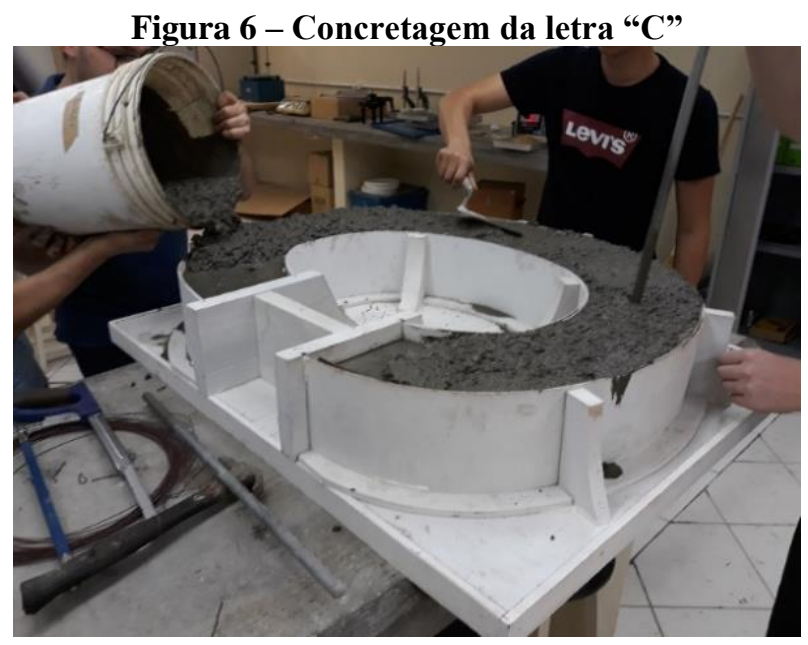

Fonte: acervo das autoras.

A última fôrma a ser concluída foi a da letra "U". Os alunos optaram por desenvolvê-la em material metálico. Além disso, ainda na fase de planejamento o grupo entendeu que haveria dificuldade para instalação desta, tendo em vista que tem sua parte inferior curva e deveria ficar em pé. Por isso, o grupo montou a fôrma já com a fundação da letra, conforme pode ser visto na Figura (a), para garantia da estabilidade final. O gabarito foi desenhado em uma placa de madeira de $0,90 \times 1,05 \mathrm{~m}$ e nesta foi anexada outra placa de $0,25 \times 0,30 \mathrm{~m}$ para ser usada como base para a fundação da letra. 
Assim como foi feito para a letra "C", foram inseridos calços de madeira por todo o contorno da letra para guiar a fôrma metálica, (Figura (b)). Foram, também, colocadas escoras em madeira nas regiões retas para evitar abaulamento destas. No centro da letra foram inseridos, ainda, apoios entre as escoras para evitar movimentação da fôrma causada pela concretagem. $\mathrm{O}$ aço dessa letra foi montado em empresa produtora de estruturas pré-moldadas da cidade, onde um dos alunos trabalha. Assim, a armadura foi executada em aço CA-50 de 6,3 $\mathrm{mm}$, e toda a montagem e ligações com estribos foi soldada para garantir o dimensionamento.

Figura 7 - Fôrma para a letra "U" executada com fundação (a), em estrutura metálica com base e escoras em madeira (b)

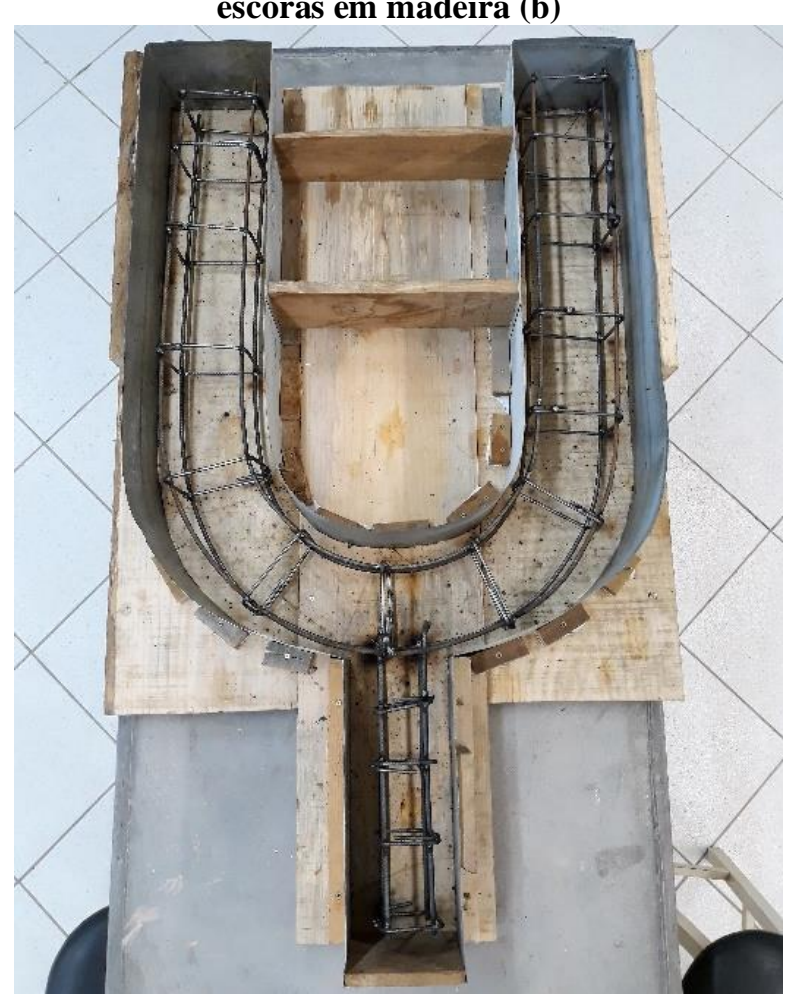

(a)

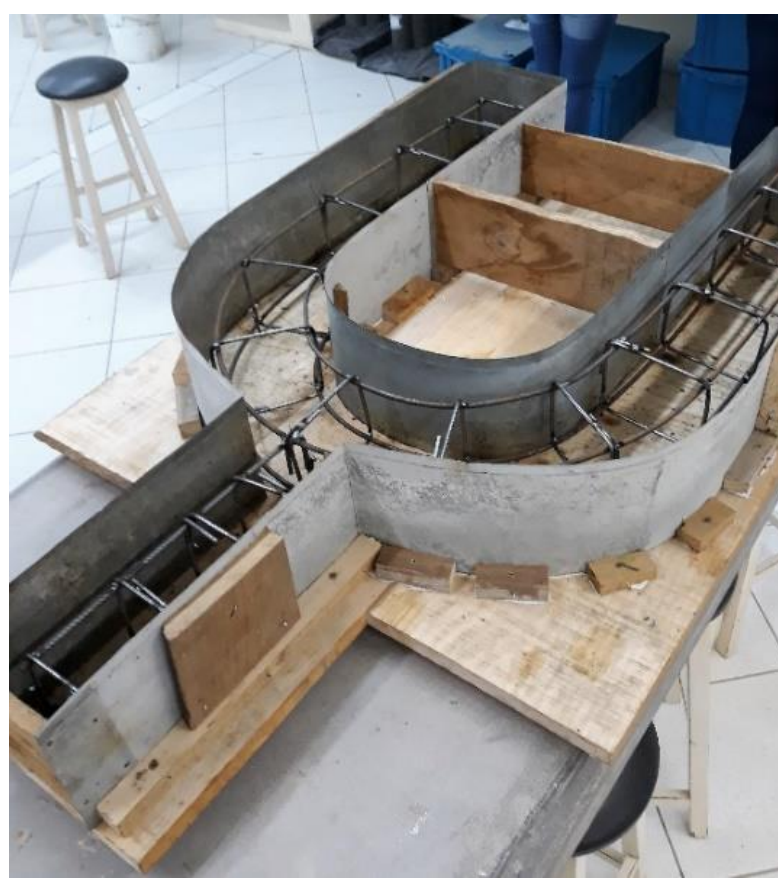

(b)

Fonte: acervo das autoras.

O concreto misturado para essa letra teve a mesma composição e fluidez do concreto da letra "C", ou seja, apresentou consistência plástica. Assim, o adensamento foi garantido por meio de vibrador elétrico de imersão, conforme apresentado na Figura (a). Verificouse que, para este caso, houve vazamento de pasta de cimento nas áreas de ligação da fôrma metálica com a base de madeira (Figura (b)), fato que pode ter ocorrido devido à maior vibração gerada pelo aparelho utilizado no adensamento, ou então por frestas deixadas entre os dois materiais. 
Figura 8 - Adensamento do concreto da letra "U" (a) e aspecto final da letra logo após a moldagem (b)

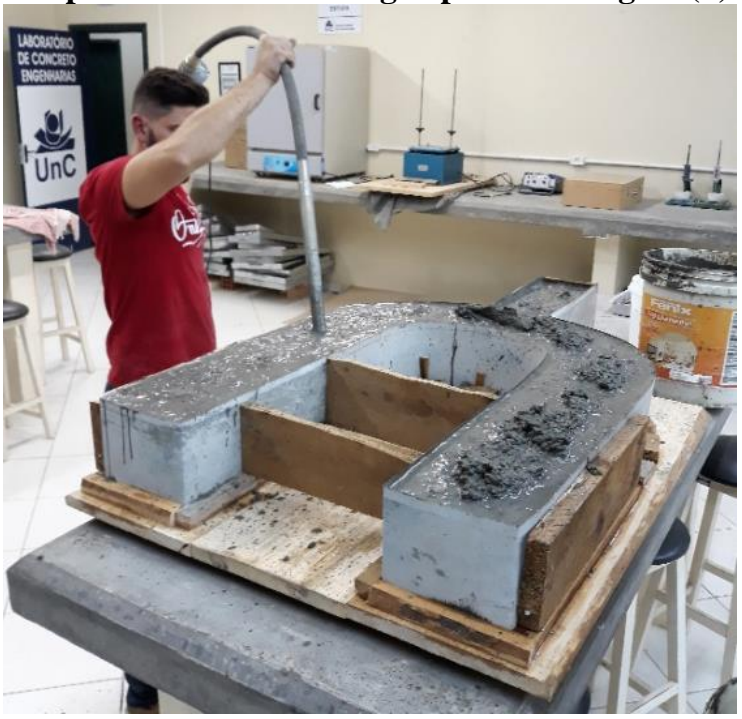

(a)

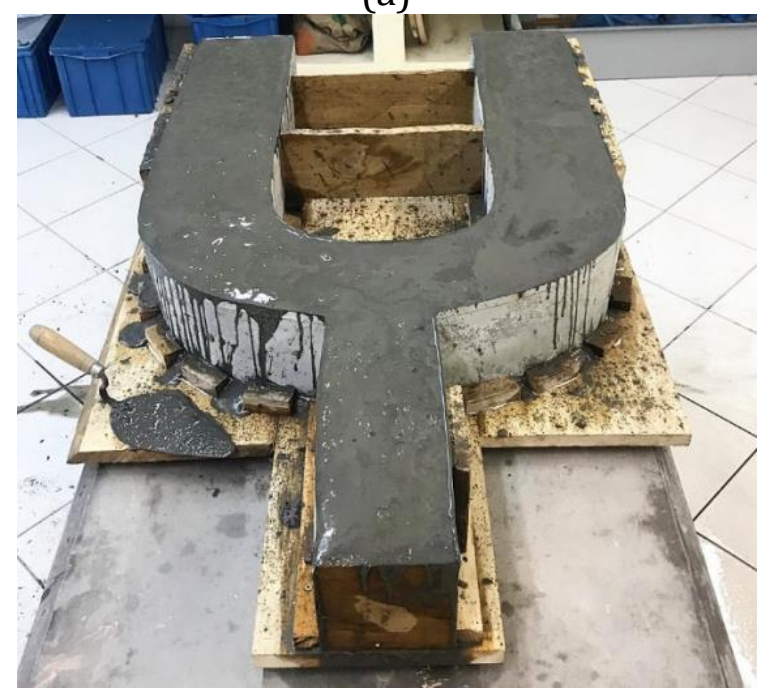

(b)

Fonte: acervo das autoras.

\section{Colocação das letras}

Primeiramente, foi definido o local exato onde as letras seriam colocadas. A direção do campus orientou que a instalação ocorresse junto ao gramado próximo ao estacionamento do acesso norte do campus, conforme indica a Figura. Além disso, em uma visita ao local, ficou definido o local exato, determinando-se inclusive a distância em relação à arvore mais próxima.
Figura 9 - Localização do letreiro no campus

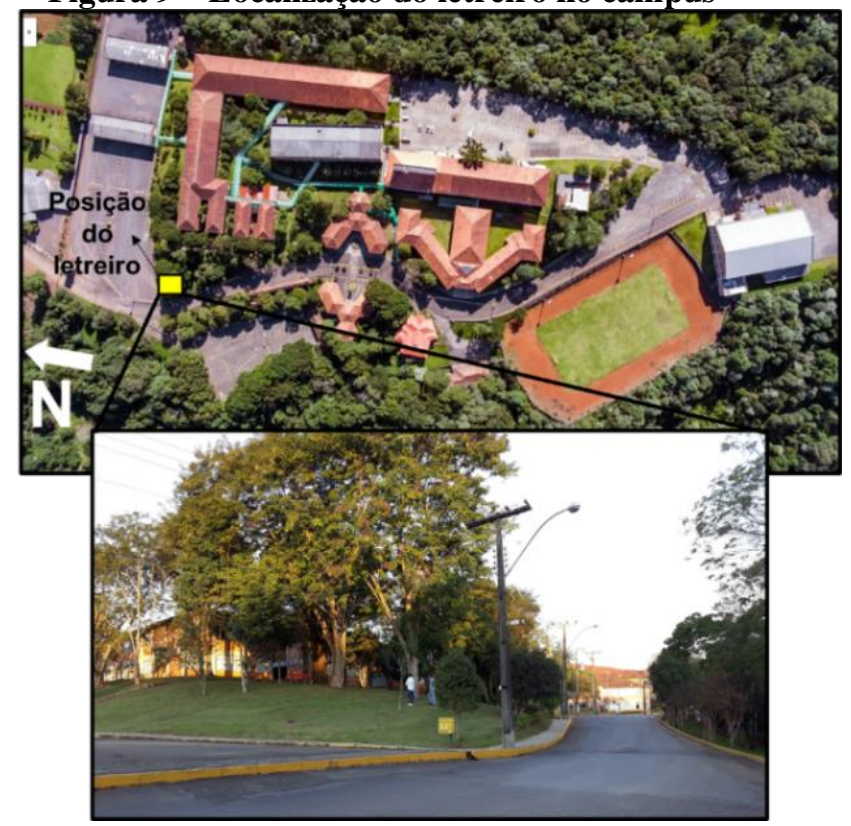

Fonte: acervo das autoras.

O processo de colocação das letras iniciou pela escavação do local. Para a sapata foi destinada uma área de 3,00 x 0,70 m, e a profundidade escavada foi de $15 \mathrm{~cm}$ na parte frontal e $30 \mathrm{~cm}$ na parte posterior. Isso ocorreu porque o terreno é inclinado e com o objetivo de que toda a sapata tivesse espessura mínima de $25 \mathrm{~cm}$.

Foi, então, realizada a marcação de onde seria colocada cada letra, isso porque se fez necessário escavar alguns centímetros a mais para a inserção da fundação da letra "U". Caso isso não fosse feito, a parte inferior desta ficaria em cota acima do nível superior da sapata. Assim que escavado esse local, a letra foi colocada em pé, fixada na base e apoiada no corpo, conforme apresenta a Figura .

Tendo-se escorado a letra "U', iniciou-se a montagem das fôrmas na parte frontal e laterais da sapata. Estas foram executadas com tábuas de madeira escoradas com ripas também em madeira. Então, foi realizada a disposição de leito de brita 1 no fundo da cava. Acima deste, foi colocada malha de aço CA-50 de $6,3 \mathrm{~mm}$, dispondo uma barra a cada $10 \mathrm{~cm}$ na lateral menor da sapata $(0,70 \mathrm{~m})$ e a cada $20 \mathrm{~cm}$ na lateral maior $(3,00 \mathrm{~m})$. Acima da armadura e do leito de brita foram dispostos pedaços de corpos de prova de concreto como forma de enchimento e redução de consumo de mais concreto (Figura ). Os corpos de prova já 
estavam rompidos pelo ensaio de resistência à compressão e foram provenientes dos concretos desenvolvidos pelos próprios alunos na disciplina.

Após, foi misturado novo concreto para enchimento da sapata até a espessura de $25 \mathrm{~cm}$. Este concreto teve consumo de cimento reduzido para $290 \mathrm{~kg} / \mathrm{m}^{3}$ e a relação água/cimento foi mantida. Com o concreto ainda fresco, foram inseridas na sapata barras de aço com comprimento aproximado de 30 $\mathrm{cm}$. As barras foram colocadas na vertical, deixando-se esperas de aproximadamente 15 $\mathrm{cm}$ acima do nível superior da sapata (Figura ). Essas esperas foram colocadas exatamente nos pontos em que as letras " $n$ " e " $C$ " seriam posicionadas e serviriam de ligação e fixação dessas letras com a sapata, tendo em vista que elas não possuíam fundação pré-executada. Para isso, foram determinadas as dimensões exatas das letras "n" e "C" já prontas, somado o espaçamento entre as letras e definido o ponto onde a barra seria inserida na parte inferior de cada letra.

Após isso, aguardou-se sete dias para a próxima etapa, período necessário para que o concreto da sapata apresentasse mínima resistência necessária aos esforços que seriam aplicados no entorno das esperas de aço. Então, para a colocação das letras " $n$ " e "C" em pé, foram feitas furações em suas bases com furadeira e broca $5 \mathrm{~mm}$, aplicando-se movimentos circulares para alargar brevemente o furo. Em seguida, iniciou-se o processo de encaixe dos furos nas esperas: as letras que estavam deitadas no gramado tiveram suas bases aproximadas das esperas de aço, foi ajustado o alinhamento destas e procedeu-se com o levantamento da letra encaixando a espera no furo (Figura ). Foram necessários ajustes para o nivelamento correto das letras.
Figura 10 - Encaixe da fundação e escoramento da letra "U" no valo da sapata

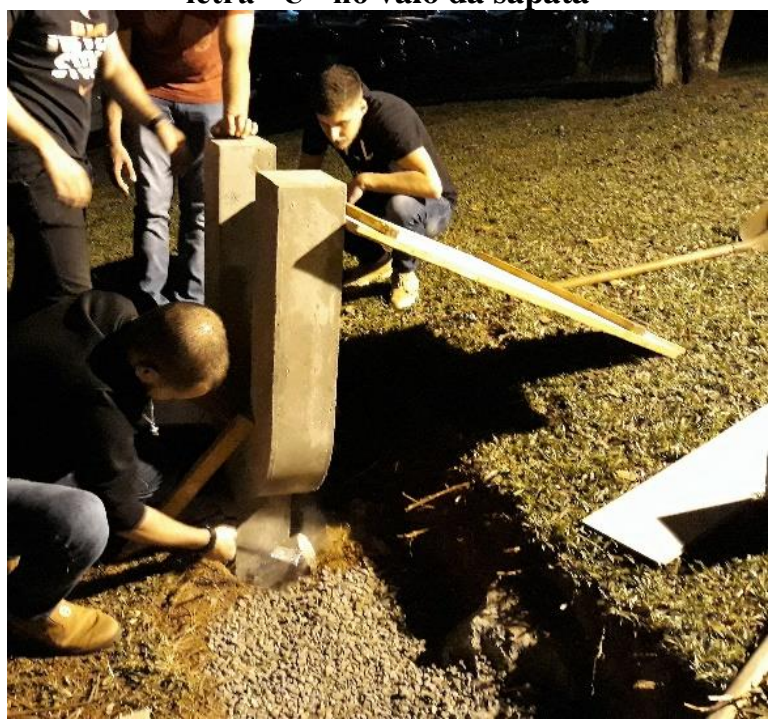

Fonte: acervo das autoras.

Figura 11 - Enchimento da sapata com corpos de

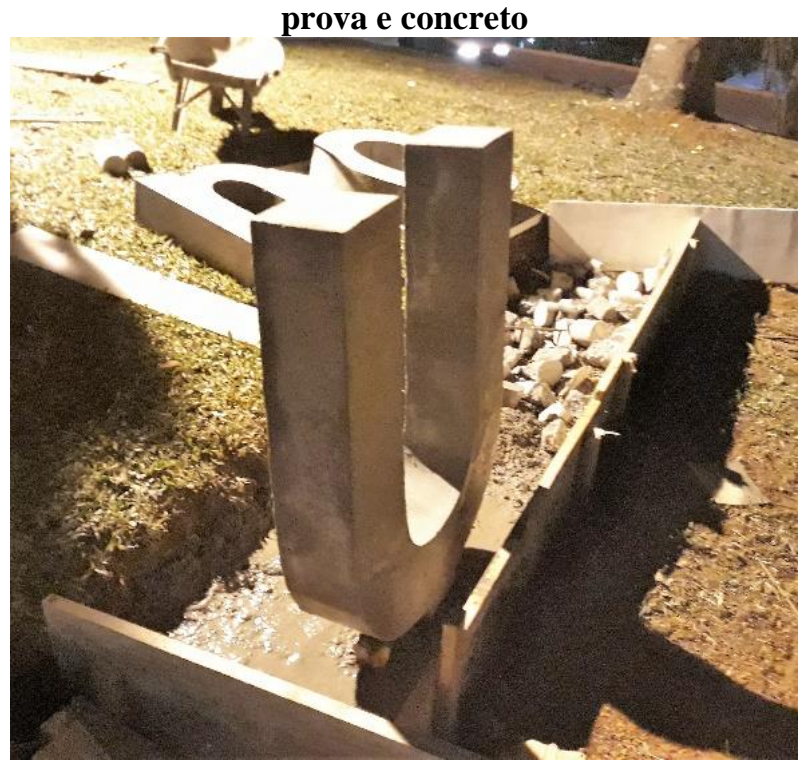

Fonte: acervo das autoras. 
Figura 12 - Inserção das esperas de aço durante a concretagem da sapata

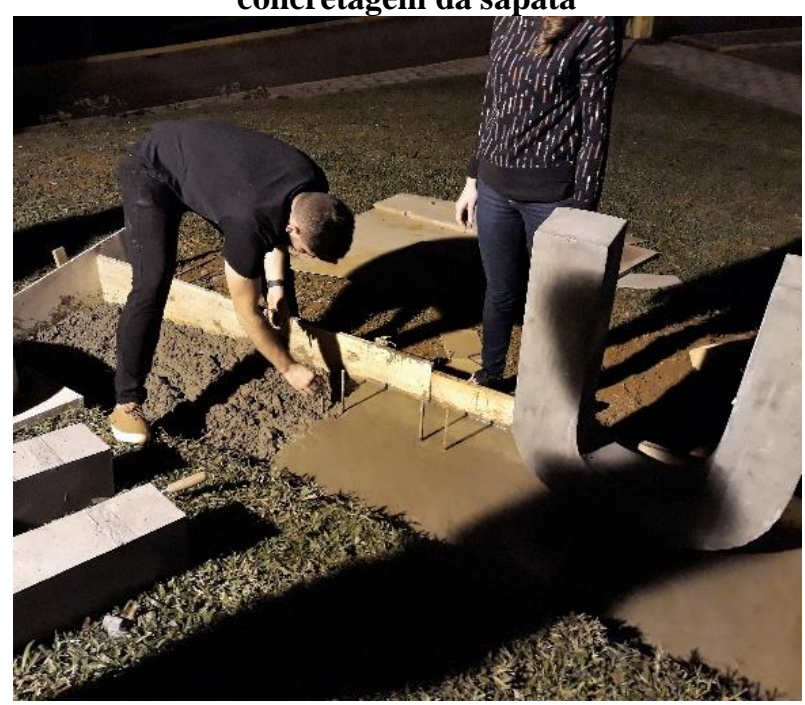

Fonte: acervo das autoras.

Figura 13 - Inserção das letras nas barras deixadas como espera

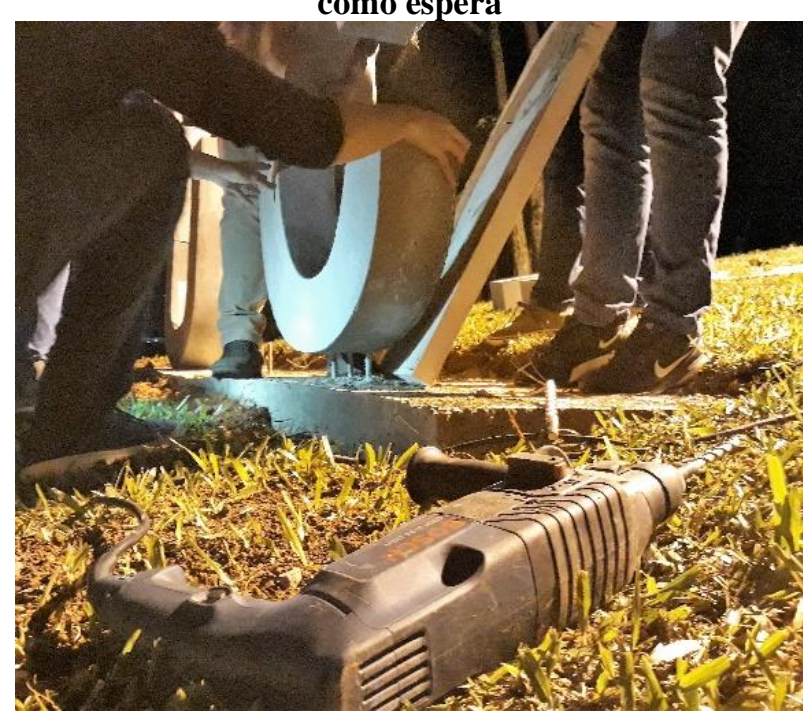

Fonte: acervo das autoras.

Após a conclusão da colocação das letras, foi feito lixamento superficial destas e deu-se por concluída a atividade prática da disciplina. $\mathrm{O}$ resultado do letreiro em concreto armado instalado é apresentado na Figura .
Figura 14 - Letreiro em concreto armado concluído

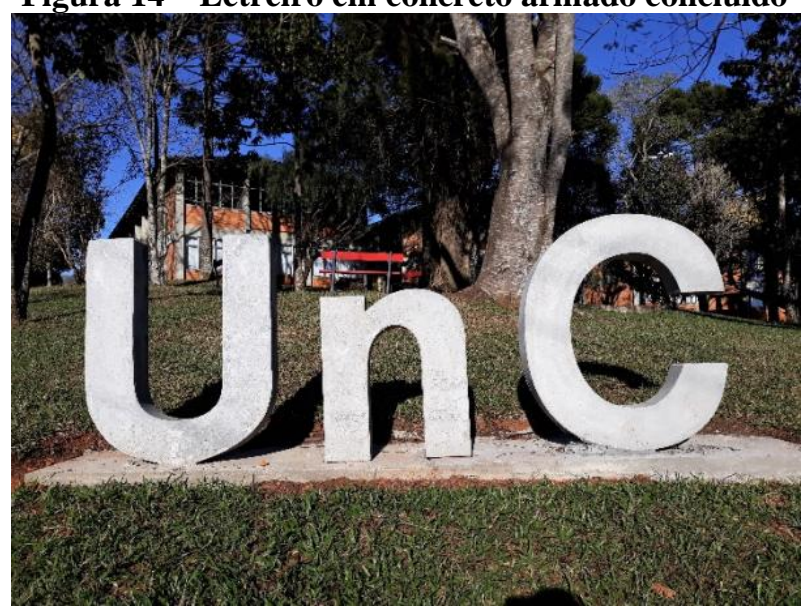

Fonte: acervo das autoras.

\section{Avaliação da satisfação da atividade}

Dos quinze alunos que compunham a turma, oito responderam ao questionário proposto. As respostas estão apresentadas na Figura em gráficos pizza cujas fatias apresentam coloração desde o vermelho até o azul que representam, respectivamente, da menor para a maior satisfação.

Figura 15 - Respostas ao questionário aplicado a partir da atividade prática

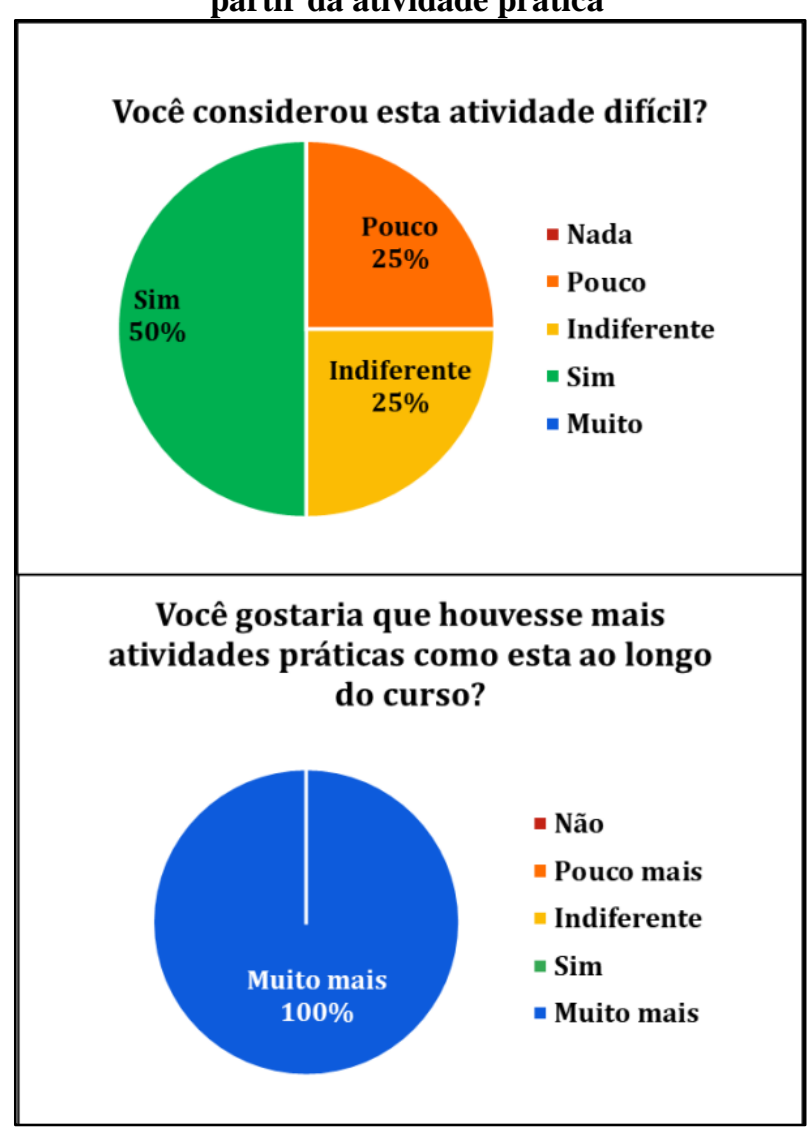




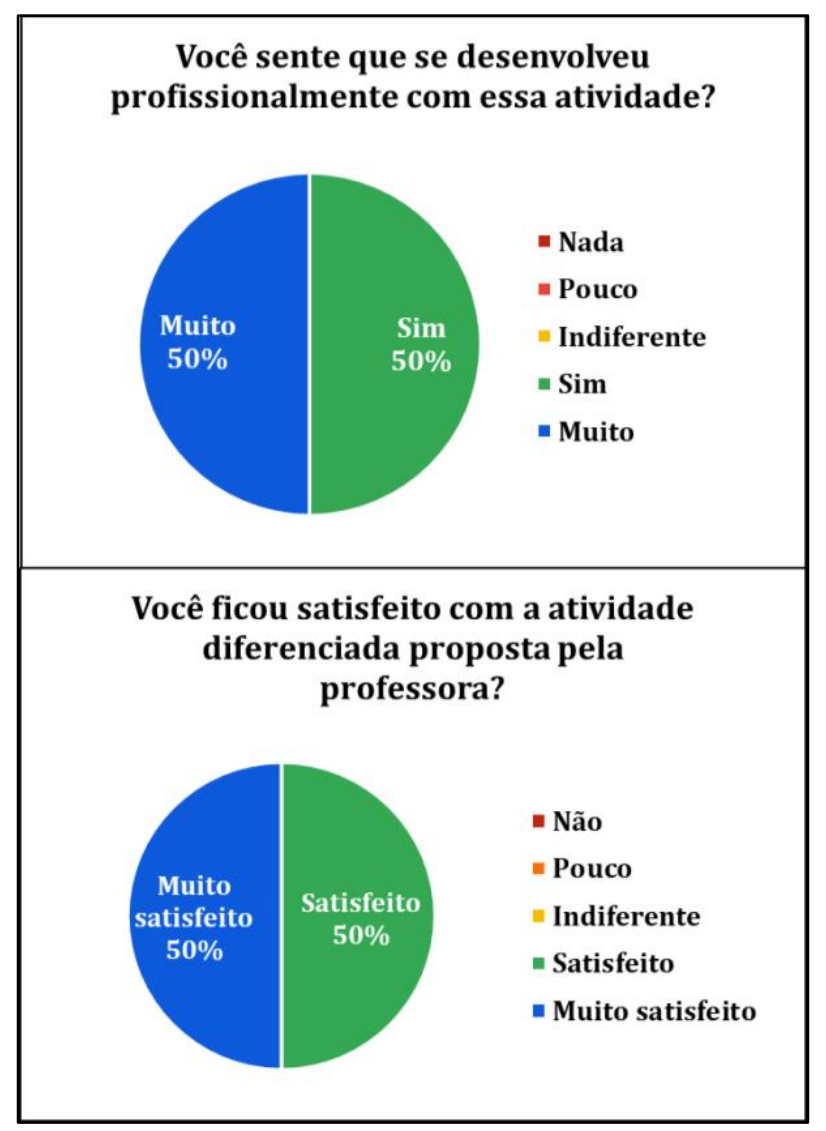

Fonte: elaborada pelas autoras.

Em relação à última pergunta da Tabela , apenas um aluno respondeu: "Parabéns para a professora pelo empenho e criatividade."

Os resultados para a primeira pergunta "Você considerou esta atividade difícil?" mostraram que metade dos alunos acharam a atividade difícil, enquanto a outra metade se dividiu em pouco difícil ou indiferente. Tais respostas podem ter relação com a já colocação profissional de parte dos alunos no mercado de trabalho. Dessa maneira, atividades como a montagem de fôrmas, armaduras e a concretagem de elementos estruturais faz parte de seu cotidiano e a dificuldade não foi percebida.

Quando perguntados: "Você gostaria que houvesse mais atividades práticas como esta ao longo do curso?", todos mostraram interesse na realização de muito mais atividades práticas como a desenvolvida. A terceira pergunta "Você sente que se desenvolveu profissionalmente com essa atividade?" dividiu os resultados entre "muito" e "sim", mostrando apenas respostas positivas, que se diferem na intensidade, possivelmente pela situação da experiência profissional dos alunos descrita anteriormente. A mesma situação foi vista para a pergunta "Você ficou satisfeito com a atividade diferenciada proposta pela professora?", que também obteve apenas respostas positivas como "Muito satisfeito" e "Satisfeito", o que torna possível ver que a atividade desenvolvida agradou a todos os alunos.

\section{CONCLUSÕES}

O modelo tradicional de ensino não é capaz de proporcionar o desenvolvimento completo de profissionais para o mercado de trabalho e a engenharia é uma área que necessita de profissionais com diversas habilidades. Para se aproximar disso, as metodologias ativas estão sendo cada vez mais buscadas e utilizadas nos cursos de ensino superior.

Este artigo descreveu e avaliou os resultados da implantação de uma atividade prática, considerada como metodologia ativa, realizada em uma disciplina final do curso de Engenharia Civil. A atividade proposta aos alunos foi a construção de letras de concreto armado para serem utilizadas como letreiro da instituição. A turma foi dividida em grupos, cada grupo responsável por uma letra. As dimensões foram repassadas pela professora e os alunos possuíam a autonomia para determinar e planejar como seria realizada a confecção das suas letras.

Verificou-se que o desafio foi concluído com o emprego de soluções diferentes a partir de cada grupo. Os alunos puderam perceber que não há apenas uma forma exata ou pré-definida de se obter o sucesso de um projeto. Reafirmaram a necessidade do planejamento das atividades e da necessidade de estudar todos os detalhes do projeto. $\mathrm{Na}$ atividade apresentada neste trabalho, alguns grupos focaram apenas na execução da letra, sem pensar previamente na instalação, o que gerou maior dificuldade na atividade final. A partir disso, um grupo adiantou a solução e facilitou a colocação da letra.

A partir da avaliação de satisfação da atividade, é possível verificar que a metodologia utilizada agradou aos alunos. Os resultados mostraram que todos os alunos que responderam ao questionário se sentiram 
satisfeitos ou muito satisfeitos com a atividade desenvolvida e gostariam que houvesse mais atividades como essa. $\mathrm{Na}$ opinião dos alunos outros benefícios também foram alcançados, como o desenvolvimento profissional dos estudantes. A observação das atitudes dos alunos durante a realização das atividades também demonstrou que o engajamento deles na aprendizagem afeta positivamente na sua formação.

Com base no que foi apresentado, as metodologias ativas se mostraram eficazes no ensino de disciplina final do curso de Engenharia Civil, indicando vantagens similares àquelas relatadas na literatura $\mathrm{e}$ mostrando o interesse dos alunos por mais atividades desse tipo. Os resultados obtidos incentivam a continuidade ao uso dessa metodologia também em outras disciplinas.

\section{AGRADECIMENTOS}

As autoras agradecem à Universidade do Contestado pela disponibilidade de infraestrutura e materiais para a realização desse trabalho.

\section{REFERÊNCIAS}

BARDINI, V. S. DOS S.; SPALDING, M. Aplicação de metodologias ativas de ensinoaprendizagem: experiência na área de engenharia. Revista de Ensino de Engenharia, v. 36, n. 1, p. 49-58, 2017.

BATTESINI, M.; MATEUS, A. L. S. S. Aprendendo com aviões de papel: metodologias ativas no ensino em engenharia de produção. Revista de Ensino de Engenharia, v. 37, n. 3, p. 81-94, 2018.

BRESSANE, A. et al. Aprendizagem baseada em dinâmicas: Uma proposta pedagógica para formação integral na engenharia. Revista de Ensino de Engenharia, v. 36, n. 1, p. 59-71, 2017.

CARVALHO, L. F. DE et al. Aulas interdisciplinares como ferramenta para motivação de ingressantes em engenharia. Revista de Ensino de Engenharia, v. 37, n. 2, p. 46-51, 2018.
CHINAGLIA, E. DE F.; SANTOS, R. B. B. Aprendizagem ativa para turmas grandes em salas de aula convencionais. Revista de Ensino de Engenharia, v. 37, n. 2, p. 3-11, 2018.

CORRÊA, V. A. ET AL. Aplicação da ferramenta PDCA como metodologia ativa em uma disciplina de lógica no curso de engenharia. VI SECSimpósio de Ensino de Ciências, v. 5, n. $1,2019$.

CORTEZ, J.; PASSOLD, F. Befaster: a aplicação lúdica da engenharia para a construção do conhecimento. Revista de Ensino de Engenharia, v. 38, n. 1, p. 107-114, 2019.

MOTA, R.; MARTINS, R. As políticas do MEC para para a educação superior e o ensino de engenharia no Brasil. Revista de Ensino de Engenharia, v. 27, n. 3, p. 61-68, 2008.

NASCIMENTO, Messias Rosa do. Novas Abordagens Sobre a Educação Brasileira e as Inovações Tecnológicas. Florianópolis. Dissertação (Mestrado em Engenharia de Produção) - Programa de Pós-Graduação em Engenharia Produção da Universidade Federal de Santa Catarina, UFSC, 2001.

ROCHA, H. M.; LEMOS, W. D. M. Metodologias Ativas: Do Que Estamos Falando? Base Conceitual E Relato De Pesquisa Em Andamento. Anais... IX Simpósio Pedagógico e Pesquisas em Comunicação, p. 12, 2014.

SANT'ANNA, A. G.; FRANÇA, Â. Aprendizagem nas práticas de uma equipe de competição de engenharia. Revista de Ensino de Engenharia, v. 39, n. 2, p. 75-84, 2019.

SENADOR, A. et al. Proposição de melhorias no ensino de engenharia por meio de atividades não convencionais. Anais... XLIV - Congresso Brasileiro de Educação em Engenharia, p. 10, 2016.

SILVA, W. A. et al. Avaliação das Estratégias de Ensino no Curso de Engenharia Civil da Universidade Federal de Goiás - Regional Catalão. Revista de Ensino de Engenharia, v. 35, n. 1, p. 13-24, 2016. 


\section{DADOS BIOGRÁFICOS DOS AUTORES}

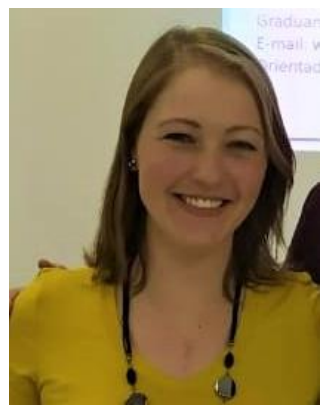

Tatiane Isabel Hentges é formada em Engenharia Civil pela Unisinos (2016) e possui mestrado em Engenharia Civil pela mesma instituição (2018). Atualmente é professora na Universidade do Contestado junto ao campus Concórdia atuando na graduação em Engenharia Civil e no Programa de Mestrado Profissional em Engenharia Civil, Sanitária e Ambiental (PMPECSA).

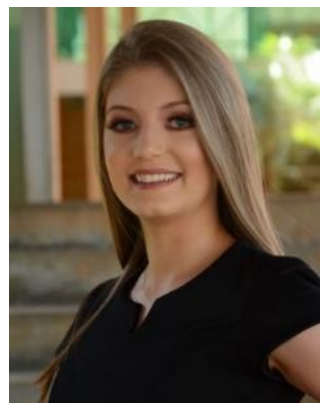

Tainá Seidel Durante é formada em Engenharia Civil pela Universidade do Contestado (2019). Atualmente é mestranda no Programa de Mestrado Profissional em Engenharia Civil, Ambiental e Sanitária, pela Universidade do Contestado.

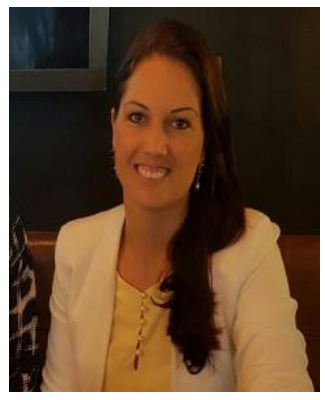

Tania Valentim de Lima Fantin é formada em Engenharia Civil pela Universidade do Oeste de Santa Catarina (2010) e especializada em Engenharia Civil pela mesma instituição (2015). Mestranda no Programa de Mestrado Profissional em Engenharia Civil, Ambiental e Sanitária, pela Universidade do Contestado. Atua como engenheira civil no Instituto Federal Catarinense - Campus Concórdia, SC. 